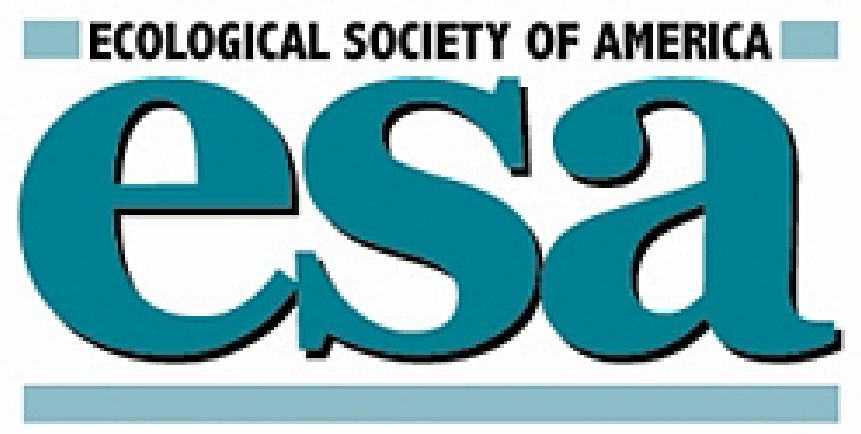

Population Stability of a Tropical Lizard

Author(s): Robin M. Andrews

Source: Ecology, Vol. 72, No. 4 (Aug., 1991), pp. 1204-1217

Published by: Ecological Society of America

Stable URL: http://www.jstor.org/stable/1941094

Accessed: 12/03/2014 14:33

Your use of the JSTOR archive indicates your acceptance of the Terms \& Conditions of Use, available at http://www.jstor.org/page/info/about/policies/terms.jsp

JSTOR is a not-for-profit service that helps scholars, researchers, and students discover, use, and build upon a wide range of content in a trusted digital archive. We use information technology and tools to increase productivity and facilitate new forms of scholarship. For more information about JSTOR, please contact support@jstor.org. 
Copyright by the Ecological Society of America. Robin M. Andrews 1991. Population Stability of a Tropical

Lizard. Ecology 72:1204-1217. http://dx.doi.org/10.2307/1941094

Ecology, 72(4), 1991, pp. 1204-1217

(C) 1991 by the Ecological Society of America

\title{
POPULATION STABILITY OF A TROPICAL LIZARD ${ }^{1}$
}

\author{
ROBIN M. ANDREWS \\ Department of Biology, Section of Ecology, Virginia Polytechnic Institute and State University, \\ Blacksburg, Virginia 24061 USA
}

\begin{abstract}
Populations of the lizard Anolis limifrons were censused for $19 \mathrm{yr}$ at the Lutz site on Barro Colorado Island (BCI) and for $4 \mathrm{yr}$ at 20 additional sites in central Panama. Census data provided estimates of population density at the end of the wet season (December) and indices of per-capita food intake and annual recruitment. Year-to-year changes in density of as much as 5- to 8-fold were observed at Lutz over $19 \mathrm{yr}$ and of 2to 3 -fold were observed over $4 \mathrm{yr}$ at other sites. Changes in population density at $11 \mathrm{BCI}$ sites were synchronous over 1983-1986, while population density fluctuated independently at non-BCI sites. Populations of $A$. limifrons exhibited significantly greater generation-togeneration variability than populations of West Indian Anolis and of lizards in temperatezone habitats (mostly arid lands in North America). An index of per-capita food intake was negatively related to density both for temporal comparisons at Lutz and for spatial comparisons among sites. The relative number of young individuals at the end of the wet season was negatively related to population density and positively related to an estimate of food intake. Partial correlations indicated that the positive association between the relative number of young individuals in the population and food intake was independent of the negative association between food intake and population density. Recruitment was thus depressed when density was high and enhanced when food was relatively abundant. Despite the potential for density-dependent regulation, Anolis limifrons populations are highly unstable, presumably because of random perturbations of the environment. Rainfall is implicated causally although population density was only weakly associated with rainfall-density at BCI was positively associated with rainfall during the dry season and negatively associated with rainfall during the wet season and with total annual rainfall. Population attributes that contribute to instability are rapid population turnover and a middle-level trophic position in a complex food web.
\end{abstract}

Key words: Anolis limifrons; density dependent; density independent; food limitation; Iguanidae; Panama; population density; population regulation; population stability; tropical lizard; tropical rainforest.

\section{INTRODUCTION}

Until recently, ecologists assumed that populations in tropical environments would exhibit low-amplitude fluctuations in population density and that controls on population density would result largely from densitydependent interactions with other species. These assumptions followed from two observations: high species diversity of tropical environments and an apparently constant physical environment. High species diversity was associated with population stability (Hutchinson 1959, Odum 1971). The absence of catastrophic reductions in population density due to seasonal temperature fluctuations was associated with $K$-selected species whose populations would exhibit low-amplitude changes in density (Dobzhansky 1950, MacArthur and Wilson 1967).

Subsequent research has shown both assumptions to be incorrect. There is no necessary correlation between species diversity and community stability (May 1973, Goodman 1975, Connell 1978). Moreover, proponents of climatic stability were misled by the relative con-

${ }^{1}$ Manuscript received 15 November 1989; revised $29 \mathrm{Au}-$ gust 1990; accepted 24 September 1990. stancy of temperature in tropical environments. In fact, when variance in amount and seasonality of rainfall is considered, tropical environments are no more stable than temperate zone environments (Ricklefs 1973:762763, Wolda 1978a), and fluctuations in population density and reproductive success of plants and animals in the tropics are comparable to those observed in temperate regions (Fogdon 1972, Wolda 1978a, b, Andrews and Rand 1982, Foster 1982, Terborgh 1986).

Long-term studies provide critical sources of information on the stability of populations and communities. Assessment of stability requires observations that span at least the length of one generation (Connell and Sousa 1983). At present, the majority of data available to evaluate population stability represent the minimum time span-one generation (Connell and Sousa 1983, Schoener 1985). These data provide valuable information, especially for cross-taxon and cross-ecosystem comparisons. However, studies that are truly long term, i.e., observations over many generations, provide information that cannot be obtained from observations of one generation or less. First, short-term observations underestimate population variability through time (Connell and Sousa 1983, Pimm and 
Redfearn 1988). Second, long-term studies can provide insights into the environmental processes that are causal for changes in population density (Andrews and Rand 1982). Third, long-term studies facilitate assessment of geographic variation in population density (Hengeveld and Haeck 1982). Fourth, long-term studies provide the best data for interpretation of evolutionary processes. For example, the evolution of life history attributes may be more influenced by "rare" climatic events than "average" conditions. Populations of a Darwin's finch had been followed for $11 \mathrm{yr}$ before an El Niño year when females produced more than onehalf of their lifetime fledglings (Gibbs and Grant 1987). Similarly, Abts (1987) documented wide variation in reproduction in his 7-yr study on demography of chuckwallas.

In this paper I discuss the results of a long-term study on the tropical iguanid lizard Anolis limifrons in central Panama. Observations span $19 \mathrm{yr}$ at one site and $4 \mathrm{yr}$ at 20 additional sites. Two major phases of this study can be distinguished, although there has been continuity of some objectives and methodologies. During the first phase of this research Andrews and Rand (1982) and Andrews et al. (1983) conducted a mark-recapture study at the Lutz site on Barro Colorado Island (BCI). Observations from 1971 through 1980 documented strong year-to-year changes in population density and a negative correlation between population density and length of the dry season (Andrews and Rand 1982). Population density at Lutz declined steadily from 1978 through 1982. Given the possibility of extinction of this population and the need to determine the generality of these observations, I initiated the second phase of this research by enlarging the spatial scale of the study. Censuses were conducted annually from 1983 through 1986 at 21 sites on BCI (including Lutz), nearby islands, and mainland areas. Censusing was continued from 1987 through 1990 at Lutz and at three other sites.

Results of these studies will be used to (1) amplify and extend previous analyses of Andrews and Rand (1982, 1990) and Andrews et al. (1983) for the Lutz site, (2) compare stability of $A$. limifrons populations with stability of other lizard populations, (3) determine the degree to which changes in population density of $A$. limifrons are synchronous among populations separated by small to moderate distances, and (4) evaluate the nature of controls on population density of this species.

\section{MATERIALS AND Methods}

\section{Life history}

The life history of Anolis limifrons in Panama is well known (Sexton et al. 1964, 1971, 1972, Andrews 1979a, $b, 1982 a$, Andrews and Sexton 1981, Andrews and Rand 1982, 1983, Andrews et al. 1983, Rand et al. 1983, Andrews and Nichols 1990). A. limifrons is a small lizard with a maximum snout-vent length (SVL) and mass $(M)$ of $50 \mathrm{~mm}$ and $2 \mathrm{~g}$, respectively, for both females and males. Females and males become sexually mature at a minimum SVL of $35 \mathrm{~mm}$. The modal size of sexual maturity for females is $41-42 \mathrm{~mm}$ SVL and all females are sexually mature at $44 \mathrm{~mm}$ SVL. Population turnover is essentially annual as $<5 \%$ of adults survive $>1 \mathrm{yr}$. Reproduction is seasonal, and most eggs are produced during the wet season (MayDecember). Hatching occurs $\approx 40 \mathrm{~d}$ after oviposition, and hatchlings are most abundant in August and September. Growth is rapid, and most individuals complete growth during the dry season; thus, the young of one wet season are the reproductive adults of the next. Comparisons in this paper are based on annual censuses conducted at the end of the wet season (usually December, but occasionally January) when population density reaches maximum annual levels due to seasonal recruitment of young individuals.

The size classes used in this paper reflect major events in the life cycle. Adults are individuals of $\geq 35 \mathrm{~mm}$ SVL. Body growth of $A$. limifrons ceases at SVLs of $\geq 44 \mathrm{~mm}$ (Andrews 1982b). Lizards reach $44 \mathrm{~mm} \mathrm{SVL}$ when they are 4-6 mo old (Andrews et al. 1983). Thus, when censuses are conducted in December, individuals $\geq 44 \mathrm{~mm}$ SVL either hatched early in the breeding season (May-August) or survived from the previous year (few eggs are laid during the dry season, JanuaryApril). As few individuals survive longer than a year, the relative number of old individuals in a population $(>43 \mathrm{~mm})$ largely represents individuals that hatched early in the breeding season. Individuals $<44 \mathrm{~mm} \mathrm{SVL}$ in December are known to have hatched within the previous 4-6 mo (July or later). The relative number of young individuals (percentage of animals $<44 \mathrm{~mm}$ SVL) in the annual census is used here as an index of annual recruitment.

\section{Study area}

Observations were conducted at BCI and surrounding areas in central Panama (Fig. 1). Vegetation is semideciduous lowland rainforest (Foster and Brokaw 1982). Forest on the southwestern side of BCI has been subject to little human disturbance over the past $200-400 \mathrm{yr}$. Forest on the northeastern half of $\mathrm{BCI}$ is regrowth from agricultural land of 100 or more years ago. Forest on the islands, peninsulas, and mainland site are comparable in age to those of young BCI forest or younger (S. J. Wright, personal communication). Thus, study sites include both mature and successional forest.

Rainfall in central Panama is seasonal (Rand and Rand 1982). At BCI an average dry season extends from late December to late April, although rainfall in December and April is highly variable. This seasonal pattern is the same for all sites although the amount of rain differs geographically. Rainfall is greater on the Atlantic side of the isthmus than the Pacific side; thus, annual rainfall at the small island sites to the northwest 

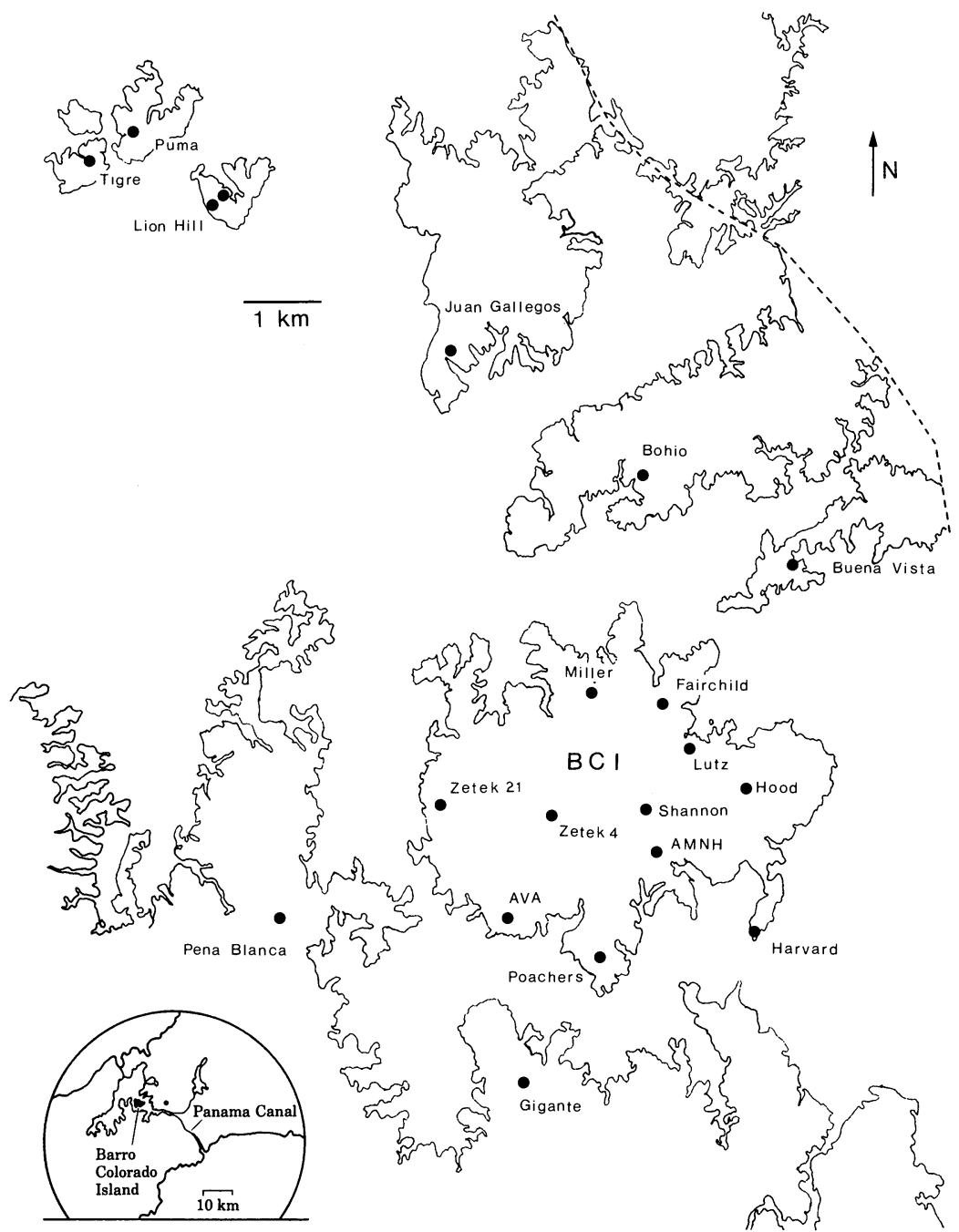

Fig. 1. Location of study sites in central Panama. The Pipeline Road site is indicated by the dot on the mainland to the right of Barro Colorado Island (BCI) in the insert map of central Panama. The dashed line at the upper right is the Panama railroad.

averages somewhat higher than at $\mathrm{BCI}$, and annual rainfall at the mainland site to the southeast averages somewhat lower. Correlation among sites in annual rainfall decreases with distance, but even sites that are relatively close (e.g., $8 \mathrm{~km}$ ) can exhibit considerable differences in rainfall in any one year (rainfall data from the Panama Canal Commission). Rainfall data for BCI were collected by the Smithsonian's Environmental Sciences Program at a station $150 \mathrm{~m}$ from the Lutz site (Windsor 1990).

\section{Consistency}

The great majority of censuses were conducted by me and A. S. Rand, by me and an assistant, or by Rand and an assistant. Participation of myself and Rand throughout this study and training of assistants by Andrews ensured that methods were consistent from one year to the next.

\section{Observations from 1971 through 1982: Lutz site}

The Lutz site is located in the $\mathrm{N}-0, \mathrm{~W}-1$ quadrat of Lutz watershed on BCI (Thorington et al. 1982). The site was $890 \mathrm{~m}^{2}$ from 1971 through 1981 and $1450 \mathrm{~m}^{2}$ in 1982 when it was increased in size to compensate for low lizard density. The canopy is closed and the understory vegetation is sparse enough to walk through easily in most places (see Andrews and Rand [1982] for a site description).

During censuses the site was searched systematically for lizards by scanning all vegetation up to about 2.5 $\mathrm{m}$. Anolis limifrons individuals typically perch on smallto medium-sized stems $<2 \mathrm{~m}$ from the ground. Lizards were captured, weighed to the nearest $0.01 \mathrm{~g}$ on a Mettler balance, measured (SVL in millimetres, accuracy: $\pm 1 \mathrm{~mm}$ ), toe-clipped for future identification, and released at the point of capture. The total population density and the density of adult males ( $\geq 35 \mathrm{~mm} \mathrm{SVL}$ ) 
TABLE 1. Study sites and observations for 1983 (observations during Jan.-Mar. 1984), 1984, 1985, and 1986 (observations during Dec.). "\#" represents the number of individuals recorded during the census and "p-h" is the person-hours spent searching for lizards. Relative density is expressed as \#/p-h.

\begin{tabular}{|c|c|c|c|c|c|c|c|c|c|c|c|c|c|c|}
\hline \multirow[b]{2}{*}{ Site } & \multirow{2}{*}{$\begin{array}{c}\text { Area* } \\
\left(\mathrm{m}^{2}\right)\end{array}$} & \multicolumn{4}{|c|}{ No. seen (\#) } & \multicolumn{4}{|c|}{ Search time $(p-h)$} & \multicolumn{5}{|c|}{ Relative density (\#/p-h) } \\
\hline & & '83 & '84 & '85 & '86 & '83 & '84 & '85 & '86 & '83 & '84 & '85 & '86 & $\bar{X}$ \\
\hline \multicolumn{15}{|l|}{ Mainland } \\
\hline Pipeline & 960 & 31 & 26 & 16 & 25 & 3.2 & 3.3 & 3.1 & 3.4 & 9.6 & 7.9 & 5.1 & 7.4 & 7.5 \\
\hline \multicolumn{15}{|l|}{ Peninsulas } \\
\hline Bohio & 960 & 8 & 8 & 3 & 9 & 2.0 & 2.3 & 2.4 & 1.7 & 4.2 & 3.8 & 1.3 & 5.8 & 3.7 \\
\hline Buena Vista & 1600 & 18 & 15 & 26 & 48 & 4.4 & 4.8 & 4.0 & 4.0 & 4.0 & 3.1 & 6.5 & 12.1 & 6.4 \\
\hline Gigante & 1600 & 28 & 23 & 36 & 57 & 3.4 & 4.0 & 4.0 & 3.0 & 8.3 & 3.3 & 9.0 & 19.2 & 10.0 \\
\hline Pena Blanca & 960 & 25 & 14 & 17 & 9 & 1.9 & 2.0 & 2.0 & 2.2 & 13.2 & 7.1 & 8.6 & 4.2 & 8.3 \\
\hline \multicolumn{15}{|l|}{ Islands } \\
\hline \multicolumn{14}{|c|}{ Barro Colorado Island } & 2.0 \\
\hline AMNH & 1600 & 1 & 3 & 5 & 9 & 3.2 & 3.0 & 3.3 & 2.2 & 0.3 & 1.1 & 1.5 & 3.9 & \\
\hline AVA & 960 & 2 & 1 & 3 & 7 & 2.4 & 2.1 & 2.2 & 1.9 & 0.8 & 0.5 & 1.4 & 3.7 & \\
\hline Fairchild & 1600 & 0 & 1 & 6 & 9 & 3.5 & 3.0 & 3.1 & 2.9 & 0.0 & 0.3 & 2.0 & 3.1 & \\
\hline Harvard & 1600 & 2 & 7 & 20 & 14 & 2.5 & 3.6 & 2.9 & 3.3 & 0.8 & 1.9 & 6.8 & 4.2 & \\
\hline Hood & 1600 & 5 & 1 & 7 & 29 & 2.7 & 2.8 & 3.5 & 3.4 & 1.9 & 0.3 & 2.0 & 8.5 & \\
\hline Lutz & 1450 & 1 & 1 & 1 & 7 & 4.0 & 2.1 & 1.7 & 2.4 & 0.2 & 0.5 & 0.6 & 3.0 & \\
\hline Miller & 960 & 0 & 1 & 6 & 3 & 2.0 & 2.2 & 1.9 & 2.3 & 0.0 & 0.5 & 3.2 & 1.3 & \\
\hline Poacher's & 1600 & 7 & 14 & 25 & 15 & 2.7 & 2.9 & 4.1 & 2.6 & 2.6 & 4.9 & 6.1 & 5.8 & \\
\hline Shannon & 1600 & 1 & 1 & 2 & 10 & 4.2 & 2.8 & 1.3 & 2.0 & 0.2 & 0.4 & 1.5 & 5.1 & \\
\hline Zetek 4 & 1000 & 0 & 0 & 0 & 0 & 2.4 & 1.9 & 2.4 & 1.8 & 0.0 & 0.0 & 0.0 & 0.0 & \\
\hline Zetek 21 & 1600 & 5 & 2 & $\cdots$ & $\cdots$ & 3.4 & 3.2 & $\cdots$ & $\cdots$ & 1.5 & 0.6 & $\cdots$ & $\cdots$ & \\
\hline Juan Gallegos & 960 & 11 & 11 & 20 & 15 & 3.1 & 2.9 & 2.6 & 2.6 & 3.6 & 3.7 & 7.6 & 5.8 & 5.2 \\
\hline Lion Hill 1 & 960 & 3 & 5 & 11 & $\cdots$ & 1.6 & 2.0 & 1.8 & $\cdots$ & 1.9 & 2.5 & 6.1 & $\cdots$ & 3.5 \\
\hline Lion Hill 2 & 960 & 23 & 9 & 10 & 10 & 1.9 & 2.4 & 2.2 & 1.9 & 12.1 & 3.8 & 4.6 & 5.2 & 6.4 \\
\hline Puma & 960 & 26 & 19 & 33 & 41 & 2.4 & 2.7 & 4.4 & 2.5 & 10.8 & 7.0 & 7.6 & 16.2 & 10.4 \\
\hline Tigre & 960 & 27 & 50 & 40 & 41 & 2.2 & 3.5 & 4.2 & 2.8 & 12.1 & 14.3 & 9.6 & 14.7 & 12.7 \\
\hline
\end{tabular}

* Because of tree and branch falls, some sites were reduced in area during the study. Sites, their new areas, and year of change are: Gigante, $1200 \mathrm{~m}^{2}$ in $1985,960 \mathrm{~m}^{2}$ in 1986; Lutz, $1380 \mathrm{~m}^{2}$ in $1984,960 \mathrm{~m}^{2}$ in 1985 and 1986; Shannon, $928 \mathrm{~m}^{2}$ in 1985 and 1986.

were estimated using Bailey's modification of the Lincoln-Peterson index (Poole 1974). For 1982 estimates were adjusted to represent an area of $890 \mathrm{~m}^{2}$, not the $1450-\mathrm{m}^{2}$ area censused. Thus, total and male population densities represent the number of individuals/ $890 \mathrm{~m}^{2}$.

\section{Observations from 1983 through 1986}

Observations were made at 21 sites (Table 1, Fig. 1): eleven located on BCI, four located on mainland peninsulas surrounding $\mathrm{BCI}$, five on islands northwest of BCI, and one on the mainland $\approx 9 \mathrm{~km}$ southeast of BCI. The Lutz and AVA (A. V. Armour trail) sites were established at BCI in 1971 and 1976, respectively, and used for long-term observations (Andrews and Rand 1982, Andrews et al. 1983). The Miller site on BCI, the sites on Juan Gallegos, Tigre, Puma, and Lion Hill islands, and the Pipeline Road site on the mainland were censused in 1980 and 1981 (Wright et al. 1984); these sites were incorporated into this study in 1983. All of the remaining sites were censused for the first time in 1983.

Areas censused were $1600 \mathrm{~m}^{2}$ or $960 \mathrm{~m}^{2}$ (for congruence with $900-\mathrm{m}^{2}$ areas established by $\mathrm{S}$. J. Wright). To facilitate censusing, each area was divided into four transects $8 \times 50$ (or 30 ) $\mathrm{m}$, and all boundaries were marked with flagging. The original boundary of AVA was maintained and Lutz had been increased to 1450 $\mathrm{m}^{2}$ in 1982 so that these sites differed somewhat in size from the others.

The criterion for site selection was that vegetation structure was similar to that at Lutz and AVA: a closed canopy and a relatively homogeneous shrub layer. Structural similarity among sites was evaluated in 1983 . Foliage density was measured with a "cover board." The cover board consisted of two metre sticks, each fastened at one end to a stake and oriented horizontally at 0.5 and $1.0 \mathrm{~m}$ above the ground. The metre sticks were painted with ten evenly spaced $2 \times 2 \mathrm{~cm}$ pink squares, $8.9 \mathrm{~cm}$ apart, on a black background. The number of pink squares visible at 6 and $12 \mathrm{~m}$ from the cover board was counted twice in each of the four transects per site, once in each direction from the center along the length of the transect. A maximum of 20 pink squares could be seen at any observation point; a lower number of squares indicated the extent to which foliage obscured visibility. In addition, a long needle was driven into the ground and the number of skewered leaves was counted at $3,6,12$, and $16 \mathrm{~m}$ from the center of each transect in each direction as a measure of litter depth. The eight values for each transect were summed for analysis.

Analyses of vegetation structure indicated that the attempt to establish a set of homogeneous sites was 
relatively successful. Most sites did not differ from either Lutz or AVA, although there was significant heterogeneity among sites in vegetation density at 6 and $12 \mathrm{~m}$ and in litter depth $(P<.05$, one-way ANOVAs). Buena Vista was the only site that differed significantly from Lutz and AVA for the two vegetation measures $(P<.05$, least significant difference [LSD] tests). Six sites (Hood, Pena Blanca, Pipeline, Zetek 21, Juan Gallegos, and Gigante) differed from AVA and Lutz in litter depth ( $P<.05$, LSD tests). Vegetation structure did not vary geographically $(P>.05$, one-way ANOVA for sites grouped as islands, $\mathrm{BCI}$, peninsulas, and mainland).

Determination of population density at the end of the wet season at a large number of sites meant that the amount of time available to work at each site had to be limited. Therefore relative population density was determined instead of total density. When I changed the procedure for estimating population density in 1983 I felt that the information gained by increasing the spatial scale of the study would more than compensate for the potential loss of continuity of the capture-recapture studies at the Lutz site.

Censuses to determine relative density were conducted between 0830 and 1430 . I and a field assistant walked slowly side by side along one edge of a transect and searched for lizards in a strip $4 \mathrm{~m}$ by $30-50 \mathrm{~m}$ and then returned along the opposite side of the transect in the same manner. The four transects were searched consecutively. All vegetation from the ground to $\approx 2.5$ $\mathrm{m}$ was carefully inspected. $A$. limifrons individuals were captured, weighed to the nearest $0.1 \mathrm{~g}$ with a Pesola spring scale, measured (SVL in millimetres, accuracy: $\pm 1 \mathrm{~mm}$ ), and toe-clipped for future identification. A stopwatch was used to measure the time required to capture lizards and record data. About $15 \%$ of lizards seen eluded capture. They were recorded and used to estimate relative density. $A$. limifrons individuals were released at the place of capture. Time spent searching was determined as the total time spent censusing each site minus the time spent on capture and data recording. To reduce bias from variance in time spent searching and to eliminate the effect of searching areas of different size, relative density is expressed as the total number of $A$. limifrons seen during each census at each site divided by the person-hours of search.

To determine within-year repeatability of census procedures, two or more censuses were conducted on six sites in 1983. Similar numbers of lizards were captured during these repeat censuses (AVA: 2 vs. 0; Buena Vista: 18 vs. 17 ; Hood: 5 vs. 9; Lutz: 1 vs. 1 vs. 1 vs. 0; Miller: 0 vs. 0; Tigre 27 vs. 29). Repeat censuses were also conducted at Lutz in 1984 (0 vs. 1 vs. 0 ) and in 1985 ( 1 vs. 1 ).

I also determined if vegetation density or the time spent searching per unit area was related to the number of lizards observed per unit area (1983 data). Sites with high vegetation density tended to take longer to search than sites with low vegetation density as indicated by cover board measurements at $6 \mathrm{~m}(P<.10$, linear regression, $\mathrm{df}=19)$. However, neither vegetation density at 6 or $12 \mathrm{~m}$ nor search time was related to the number of lizards observed $(P \gg .05$, stepwise multiple regression). Thus, comparisons among sites are not confounded by either the time spent searching or vegetation density.

Year-to-year repeatability of census procedures was evaluated by comparisons of the person-hours spent searching (times adjusted to $1600 \mathrm{~m}^{2}$, Table 1). Differences among years and sites were significant $(P<$ .001 , two-factor repeated-measures ANOVA), but the significant interaction between years and sites $(P<$ $.001)$ suggested that year-to-year variation in the time spent searching did not vary systematically among sites. Moreover, search times in 1983 and 1986 differed from search times in 1984 and $1985(P<.05$, LSD tests) with the shortest search times being in 1983 and 1986 and the longest in 1984 and 1985 . Time spent searching was unrelated to relative density, which was lowest overall in 1984 and highest in 1986.

\section{Observations from 1987 through 1990}

Observations were continued from 1987 through 1990 at a subset of the 21 populations studied the previous 4 yr, namely, AVA, Lutz, Pipeline, and Shannon. Data presented here are: (1) relative density at the Lutz site in December 1987, 1988, and 1989 and (2) estimates of the total population density and relative population density from capture-recapture censuses conducted in July 1988 at Pipeline and Shannon, in December and April 1988 at AVA and Shannon, and in June 1990 at AVA, Lutz, and Shannon.

\section{Population density and stability}

Both total density (Bailey's modification of the Lincoln index [Poole 1974]) and relative density were estimated at the Buena Vista, Hood, and Tigre sites in 1983 and at the AVA, Lutz, Pipeline, and Shannon sites in 1988-1990. Total and relative density were highly correlated (Fig. 2). Therefore, regression analysis (principle axis and regression equations were virtually identical) was used to predict total density from relative density at the Lutz site from 1983 through 1989.

Variability in population density was estimated by the standard deviation (SD) $\log _{10}$ population density (Connell and Sousa 1983). This statistic is independent of the absolute magnitude of population density. Following Connell and Sousa (1983), observations of SD $\log _{10}$ population density are grouped into classes of 0.2 SD units for comparisons of variability among sites. My use of annual censuses to measure variability from generation to generation follows Schoener's (1985) criterion that $<5 \%$ of individuals in a census were alive from the previous census. In 1983, no lizards were seen during censuses at Fairchild and Miller; 0.1 was substituted for 0 when data were log transformed. Com- 
parative data for SD $\log _{10}$ population density are from Schoener $(1985,1986 a)$ with additional data from Ferguson et al. (1980), Abts (1987), Jones and Ballinger (1987), and Strijbosch and Creemers (1988).

SD $\log _{10}$ population density varies as a function of the number of observations (Pimm and Redfearn 1988). Because most estimates of SD $\log _{10}$ population density from the literature were based on two censuses, I based comparisons with literature values on data collected in 1983 and 1984, the first 2 yr of observations at 21 sites. For the Lutz site SD $\log _{10}$ total population density was calculated for a series of nested censuses $(1+2$, $1+2+3$, etc.). The consequence of error in estimating total density from relative density for 1983 to 1989 was considered by calculating the upper and lower $95 \%$ confidence limits for each estimate of total density and also calculating SD $\log _{10}$ population density using these confidence limits.

\section{Index of condition: a correlate of food intake, fecundity, and growth}

Andrews et al. (1983) documented greater food intake (as measured by fecal output), fecundity (as measured by oogenesis), and individual growth rates at Lutz than at AVA. Moreover, an index of condition $\left(\mathrm{IC}=\mathrm{Mass}^{0.33} / \mathrm{SVL}\right)$ was greater at Lutz than AVA. This suggested that IC could be used to assess food intake, fecundity, and individual growth for A. limifrons populations. Therefore, the relationship between IC (dependent variable) and oogenesis (class variable) was evaluated using fecal output as a covariate. Because of significant site and seasonal differences in IC (Andrews et al. 1983) and significant interactions between season and other variables, separate analyses were conducted for the two sites and for the dry (January-April) and the wet (May-December) seasons. Analyses involved only females $35 \mathrm{~mm}$ or more in SVL. IC, fecal output, and fecundity were used in these analyses because they were recorded at each capture for all female lizards. Growth data were excluded because they required two captures and thus involved a relatively small subset of the data. The analysis was repeated with IC corrected for fecal mass $\left[\mathrm{IC}=\left(\mathrm{Mass}^{0.33}\right.\right.$ - Fecal Mass)/SVL]. There were no differences between the results of the two analyses.

During the dry season at Lutz, IC was significantly greater for oogenic than non-oogenic females $(P<.01)$ and there was a positive regression between IC and fecal output $(P<.01)$. During the dry season at AVA, oogenic females tended to have higher values of IC than non-oogenic females $(P<.10)$, but there was no association between IC and fecal output $(P \gg .05)$. During the wet season at both Lutz and AVA, oogenesis was not related to IC but there was a positive regression between IC and fecal output $(P<.05)$. There was no interaction between oogenesis and fecal output at Lutz or AVA sites in either season $(P>.05)$.

These intrasite comparisons indicate, as did the ini-

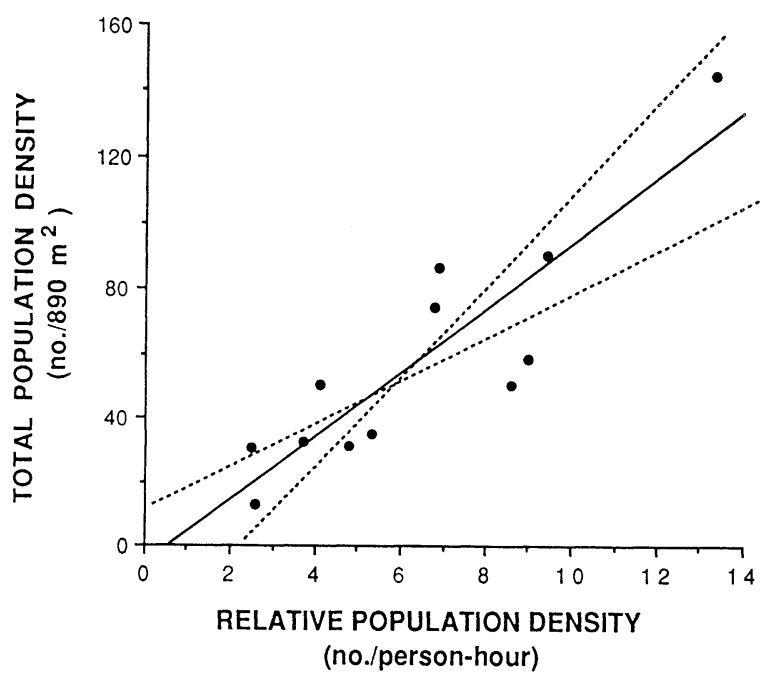

FIG. 2. Relationship between total population density and relative population density of Anolis limifrons during 12 censuses at seven sites in central Panama. The regression equation is Total density $=-5.43+9.91$ Relative density $(P<$ $\left..01, R^{2}=0.78\right)$. The dotted lines represent $95 \%$ confidence limits of the slope.

tial comparison between Lutz and AVA (Andrews et al. 1983), that IC is directly related to important energetic rate processes. Females with high values of IC have greater food intake (fecal output) and are more likely to be reproductive than females with low values of IC. The reason why IC was not related to oogenesis in the wet season at either site is that most $(>75 \%)$ adult females are oogenic in the wet season (Andrews et al. 1983). Thus, although females are yolking follicles continuously, the rate of egg production presumably varies with food intake.

Therefore, to assess food intake, fecundity, and growth for this study, IC was determined for all individuals $\geq 35 \mathrm{~mm}$ (except in 1971 when mass was not recorded). IC was not calculated for individuals $<35$ $\mathrm{mm}$ SVL because the variance of IC was very high for this size class.

\section{Rainfall and population density}

Observations at the Lutz site during the first $10 \mathrm{yr}$ of this study (1971-1980) indicated that population density was positively related to the sum of rainfall during the months of December and April, prior to late wet-season censuses (Andrews and Rand 1982). However, with four more years of data (1971-1984), population density at Lutz was negatively related to total rainfall during the year of the census, not rainfall during December and April (Andrews and Rand 1990). Thus, to provide independent tests of models that relate population density to rainfall, multiple regression analyses were used to relate relative density at Lutz from 1985 through 1989 and mean relative density at other BCI sites from 1983 through 1986 to the sum of 


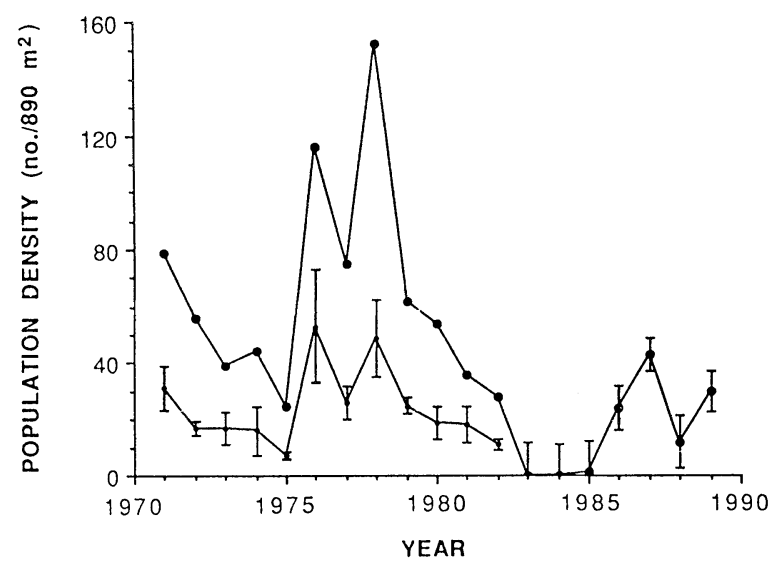

FIG. 3. Population density of Anolis limifrons at the Lutz site from 1971 through 1989 . Density of adult males $(\bullet, \bar{X} \pm$ $1 \mathrm{SE})$ and total population density $(\Theta, \bar{X} \pm 1 \mathrm{SE})$ from 1971 through 1982 were estimated using Bailey's modification of the Lincoln index (Poole 1974). Total population density \pm 1 SE from 1983 through 1989 was estimated from relative density (see Fig. 2).

rainfall in December and April and to total annual rainfall.

In addition, stepwise multiple regression was used to evaluate the relationship between total population density $\left[\log _{10} N(t)\right]$ at Lutz from 1971 to 1989 and rainfall. To account for correlation between population density at one time and some previous time, $\log _{10} N(t$ - 1) was used as an independent variable. Other independent variables were the sum of rainfall during December and April prior to censuses, total rainfall during the year of the census, and rainfall in the early (May-July) and late wet season (August-November). Rainfall amounts during the early wet and late wet seasons were used as independent variables because they indicate conditions during specific portions of the wet season.

Observations for 1981 were excluded from analyses because rainfall wass considered an extreme outlier. Annual rainfall from 1971 through 1989 averaged 2502 $\mathrm{mm}$ while annual rainfall in 1981 was $4571 \mathrm{~mm}-3.5$ SD units from the mean.

\section{Statistical analyses}

All parametric analyses were conducted using SAS procedures (SAS Institute 1982). Non-parametric analyses follow Siegel (1956).

\section{RESULTS}

\section{Population fluctuations and synchrony}

Population density at the Lutz site varied considerably from 1971 through 1989 (Fig. 3). The population exhibited peak levels in 1971, 1976, and 1978 and then declined to very low levels through 1985 . Total population density for 1983 through 1989 was estimated from relative density. During $3 \mathrm{yr}, 1983$, 1984, and 1985, estimates of total density are extrapolations beyond the range of observations (Fig. 2). Thus, these estimates should be considered as approximations. It is quite clear, however, from the small numbers of individuals ( 0 or 1 ) seen during nine censuses that the population at Lutz was at extremely low levels from 1983 through 1985.

Relative population density varied among the 21 sites $(P<.001$, two-factor repeated-measures ANO$\mathrm{VA}$ ), with mean relative densities ranging from 12.7 lizards per person-hour (p-h) at Tigre to 2.0 lizards/ $\mathrm{p}-\mathrm{h}$ at $\mathrm{BCI}$ (Table 1$)$. Relative density also varied among years $(P<.001$, two-factor repeated-measures ANOVA). LSD tests distinguished densities in 1986, densities in 1983 and 1985, and densities in 1984 as different from one another $(P<.05)$. Moreover, densities at Buena Vista, Gigante, Harvard, Hood, Lutz, Miller, and Shannon exhibited significant year-to-year variation in site-by-site analyses $(P<.05$, two-way ANOVAs).

Relative density did not change concordantly over time at all sites, as indicated by the significant interaction between sites and years $(P<.001$, two-factor repeated-measures ANOVA). This interaction is the result of synchronous increases in relative density at all $\mathrm{BCI}$ sites from 1983 to $1986(W=0.87, P<.01$, Kendall coefficient of concordance) and apparently independent fluctuations at other sites. The relative population density at Gigante and Buena Vista increased during the 4 yr while relative density at Pena Blanca and Bohio, other peninsular sites near BCI, fluctuated independently of the trend exhibited at BCI $(P<.05)$. Relative population density on other island sites and at Pipeline on the mainland did not fluctuate in concordance with the BCI populations or with each other $(P>.05)$.

\section{Population stability}

At the Lutz site SD $\log _{10}$ total population density increased with the number of nested censuses (Fig. 4). Variability increased gradually and then leveled off after about six censuses. Variability increased sharply when the population crashed in 1983 and then leveled off again after several more years. If SD $\log _{10}$ total density is calculated using the upper $95 \% \mathrm{CL}$ for estimates of density from 1983 through 1989 , the plot has a single plateau. However, this scenario is plausible only if total density was grossly underestimated for 1983 through 1985. The consistently low numbers of individuals captured during 1983-1985 and the standard errors of estimates of density (Fig. 3) indicate that the population crash was quite real, and that SD $\log _{10}$ total population density would have increased substantially as a result.

BCI sites exhibited higher SDs of $\log _{10}$ relative population density than other sites (Fig. 5) for comparisons involving the first $2 \mathrm{yr}$ of data or all $4 \mathrm{yr}(P<.01, t$ tests). For four years of data, BCI populations fell into 


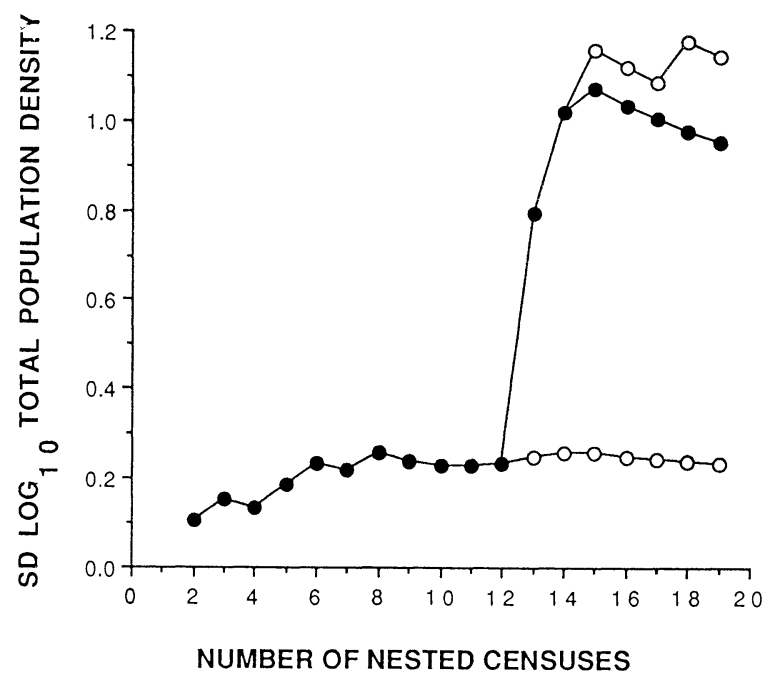

FIG. 4. SD $\log _{10}$ total population density of Anolis limifrons (measured as no. $/ 890 \mathrm{~m}^{2}$ ) for the Lutz site calculated for sequences of nested censuses ( $(\bullet)$. SD $\log _{10}$ of total population density from 1983 through 1989 is shown with the $95 \%$ confidence limits for each estimate $(\mathrm{O}$, see Materials and methods: Population density and stability).

the four lowest classes of variability and other populations in the two lowest classes of variability. Both sets of populations exhibited greater stability when SD $\log _{10}$ relative density was based on two rather than on four years, although differences were significant only for BCI populations $(P<.05, t$ tests $)$. BCI populations, which increased during 1983-1986, were more variable than non-BCI populations, which did not exhibit any consistent trend in relative density. Estimation of variability at $\mathrm{BCI}$ sites is probably confounded to some degree by sampling error at low densities. However, even at low densities, the number of lizards recorded was highly consistent for repeated censuses (see Lutz data in Materials and methods: Observations from 1983 through 1986). Thus, it is unlikely that sampling error explains differences observed between $\mathrm{BCI}$ and nonBCI sites.

\section{Density-dependent interactions}

Index of condition (IC). - Total and adult male population densities for 1971 through 1982 were highly correlated $(r=0.95, P<.001$, Pearson correlation coefficient). Because adult males are the class most reliably censused, density estimates for this class were used in subsequent analyses relating IC and percentage of animals $<44 \mathrm{~mm}$ SVL to density. Analyses using the estimate of total population density gave identical patterns but at a slightly lower level of statistical significance.

At the Lutz site IC was negatively related to adult male density (Fig. 6, $P<.001$, ANCOVA). The interaction between sex and density was not significant $(P>.05)$; thus, the regression slopes for females and males were homogeneous. However, females had sig- nificantly higher values of IC than did adult males ( $P$ $<.001)$. This difference is attributed to the mass of gonadal tissue: adult females generally carry one oviductal egg and several yolking follicles $(\approx 0.15 \mathrm{~g})$.

The regression relationships are

$$
\begin{gathered}
\mathrm{IC}_{\mathrm{female}}=2.70-0.0027 X \\
\left(F_{1,165}=39, R^{2}=0.19, P<.001\right)
\end{gathered}
$$

and

$$
\begin{gathered}
\mathrm{IC}_{\text {male }}=2.66-0.0023 X \\
\left(F_{1,262}=63, R^{2}=0.16, P<.001\right),
\end{gathered}
$$

where $X$ is the number of adult males at the end of the wet season for censuses conducted from 1972 through
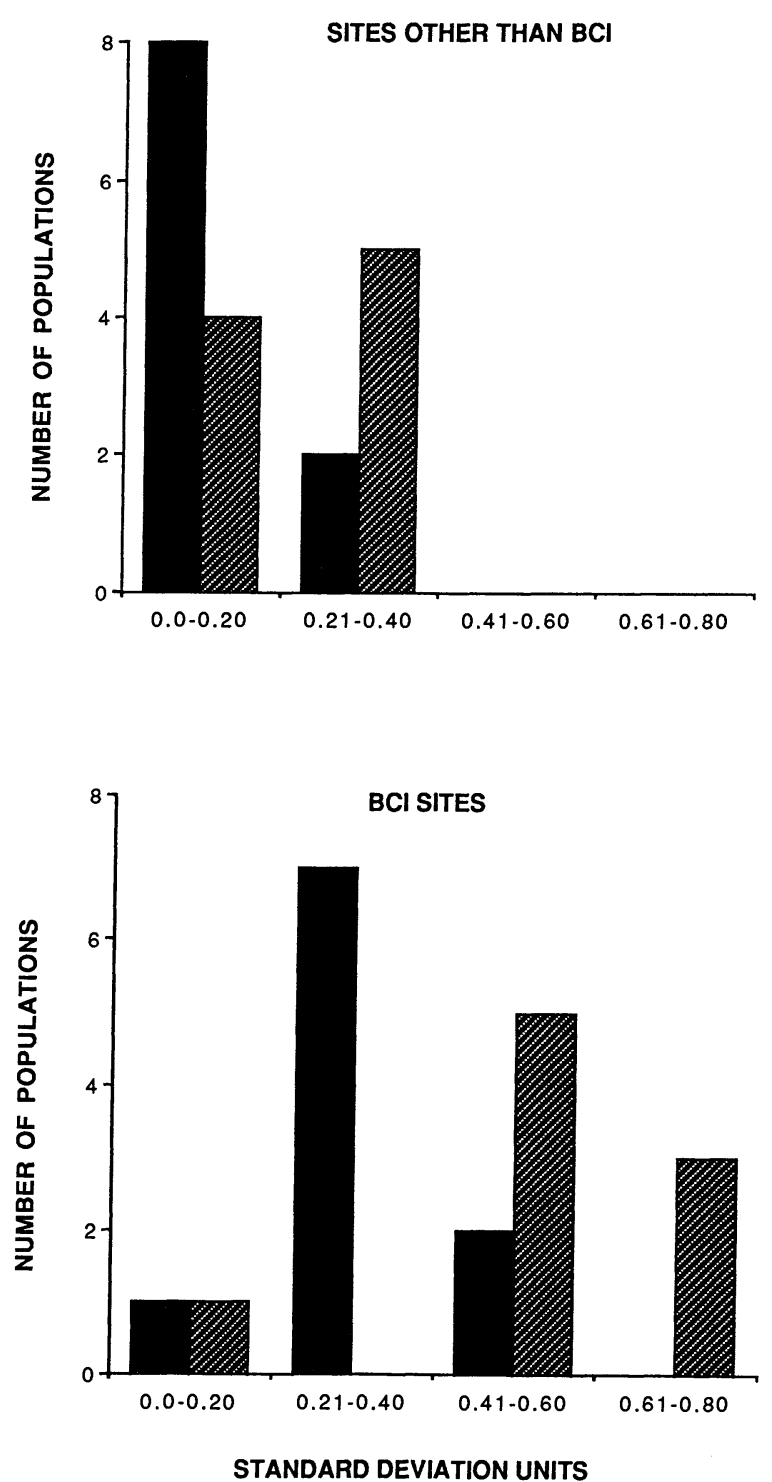

FIG. 5. Frequencies of $S D \log _{10}$ relative population density (measured as no./person-hour) for Anolis limifrons at BCI and at other sites in central Panama for the first two years of census (䡉, $n=20$; no lizards were recorded at Zetek 4) and for all

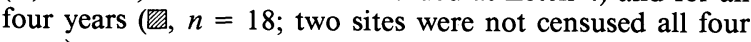
years). 


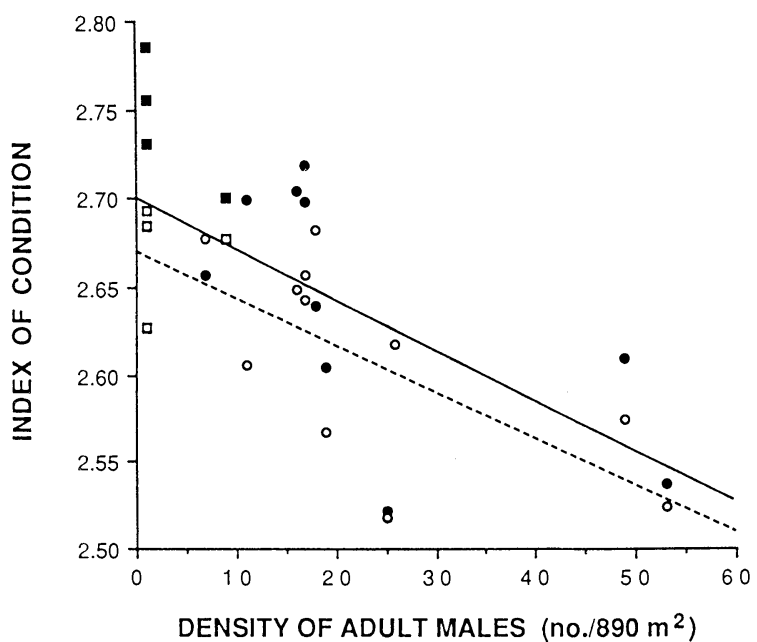

Fig. 6. The relationship between the index of condition (IC $=$ mass $^{0.33}$ divided by snout-vent length [SVL] of Anolis limifrons) and the density of adult males at the Lutz site from 1972 through 1982. Means are shown (females:,- , males: O, -----). Means for all BCI sites for 1983 through 1986 are also shown (females: $\square$; males: $\square$ ), although these data were not used in regression analysis. For 1983 through 1985 the density of adult males was arbitrarily set at one individual; for 1986 the density of adult males was set at $38 \%$ (average percentage of males for 1971 through 1982) of the estimated total population of 24 individuals.

1982. During 1983 through 1986 , when density at Lutz was relatively low, too few data on IC were collected to provide meaningful statistical comparisons with previous years. To provide some indication of the magnitude of IC at very low densities, observations at all BCI sites (including observations for January but not February or March 1983) are indicated on Fig. 6.

In comparisons among sites IC was also negatively related to relative population density (Fig. $7, P<.01$, ANCOVA). The regression slopes were homogeneous $(P>.05)$. Thus, females and males responded similarly to relative population density but females had significantly higher values of IC than males $(P<.001)$.

The regression relationships are

$$
\begin{gathered}
\mathrm{IC}_{\text {female }}=2.74-0.0035 X \\
\left(F_{1,224}=5.2, R^{2}=0.02, P<.05\right)
\end{gathered}
$$

and

$$
\begin{gathered}
\mathrm{IC}_{\text {male }}=2.68-0.0030 X \\
\left(F_{1,281}=4.3, R^{2}=0.02, P<.05\right),
\end{gathered}
$$

where $X=$ relative population density.

Relative number of young individuals $(\%<44 \mathrm{~mm}$ $S V L)$. - At Lutz from 1971-1982, the percentage of animals $<44 \mathrm{~mm} \mathrm{SVL}$ was negatively related to adult male density (Fig. 8) as

$$
\begin{gathered}
\%<44 \mathrm{~mm} \mathrm{SVL}=67.1-0.41 \text { (male density) } \\
\left(F_{1,10}=5.2, R^{2}=0.34, P<.05\right)
\end{gathered}
$$

In addition, mean IC for both females and males was positively correlated with $\%<44 \mathrm{~mm} \mathrm{SVL}(r=0.80$ and 0.71 , respectively, $n=11, P<.05$, Pearson correlation coefficients). Partial correlations were examined to evaluate the possibility that this relationship could simply be the spurious consequence of negative associations between $\%<44 \mathrm{~mm} \mathrm{SVL}$ and density and between IC and density. For both females and males, partial correlations between IC and $\%<44 \mathrm{~mm} \mathrm{SVL}$ were significant $(P<.01$ and .05 , respectively), indicating that the association is independent of population density.

Sites varied considerably in $\%<44 \mathrm{~mm}$ SVL, with values ranging from $\approx 80 \%$ at Buena Vista and Tigre to $\approx 30 \%$ at Pena Blanca and Juan Gallegos $(P<.01)$, while variation among years was relatively low (Table $2, P \gg .05$, two-way ANOVA). In a previous study (Andrews 1988) I found that survival of eggs early in the wet season at the Buena Vista, Harvard, Lutz, Poacher's, Shannon, and Tigre sites was directly proportional to $\%<44 \mathrm{~mm} \mathrm{SVL}$ at the end of the wet season $(P<.01, n=6, r=0.94)$ and was independent of relative population density $(P>.05)$. Similarly, in the present study variation in $\%<44 \mathrm{~mm}$ SVL was not related to relative population density (or to IC of females or males) $(P>.05$, Pearson correlation coefficients, comparisons among site means). These results suggest that, for comparisons among sites, $\%<44 \mathrm{~mm}$ SVL is an index of egg survival. This interpretation is supported by identical estimates of egg survival (17\%) at Lutz in 1981 and 1986 (Andrews 1982, 1988) and by results of simulation modeling (R. M. Andrews, unpublished data).

In general, $\%<44 \mathrm{~mm}$ SVL provides an index to the two components of recruitment, egg and juvenile survival. My observations suggest that, because $\%<44$ $\mathrm{mm}$ SVL largely reflects variation in egg survival for

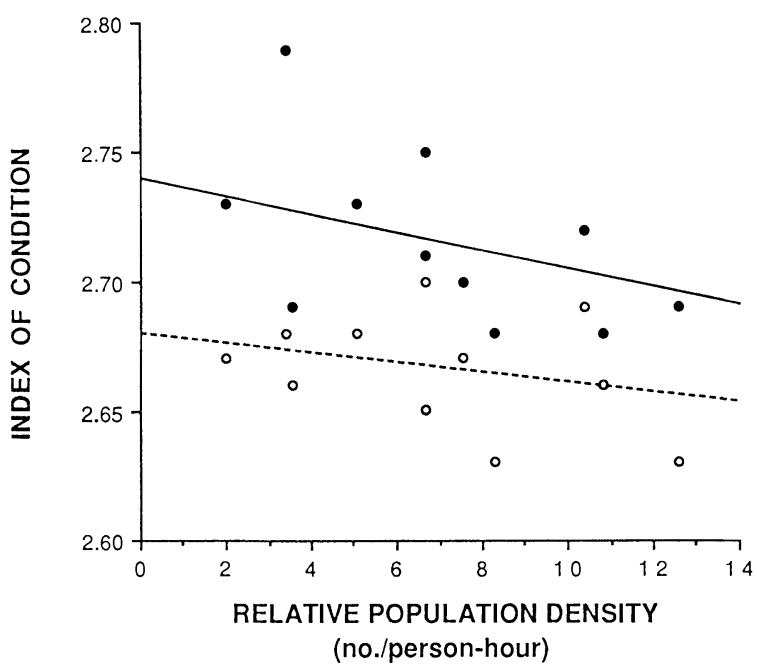

FIG. 7. The relationship between the index of condition $\left(\mathrm{IC}=\right.$ mass $\left.^{0.33} / \mathrm{SVL}\right)$ and the relative population density of Anolis limifrons at 11 sites (BCI treated as one site in this analysis) in central Panama. Means are shown (females: $\bullet$, $\longrightarrow$; males: $0, \cdot-\cdot--)$. 


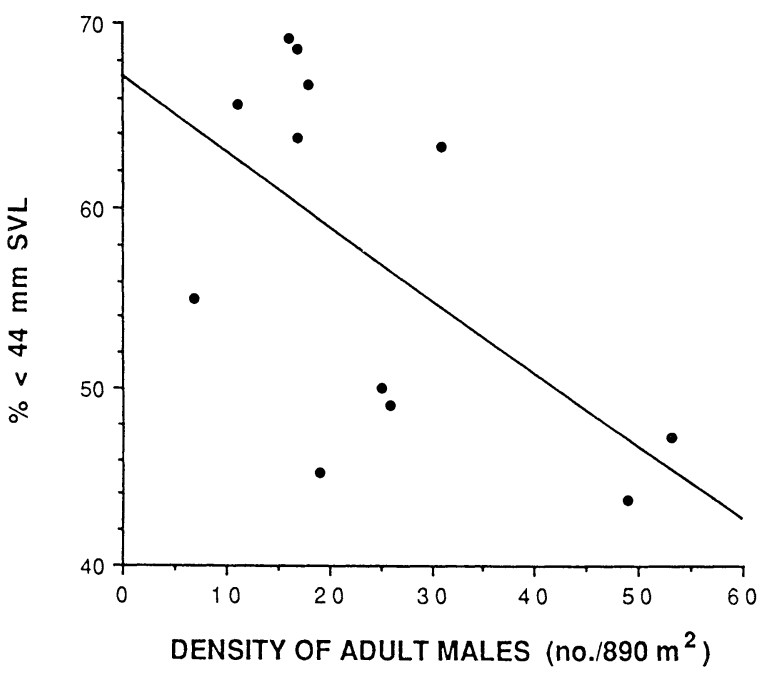

FIG. 8. The relationship between the relative number of young Anolis limifrons individuals (\% of lizards $<44 \mathrm{~mm}$ SVL) and density of adult males at the Lutz site (1971 through 1982).

comparisons among sites, $\%<44 \mathrm{~mm}$ SVL should largely reflect variation in juvenile survival for comparisons among years within sites.

\section{Rainfall and population density}

At Lutz from 1985 to 1989 relative population density was not related either to the sum of rainfall in December and April or to total annual rainfall or to the combination of these variables $(P>.05)$. Mean relative density at $\mathrm{BCI}$ from 1983 through 1986, on the other hand, was related to the sum of rainfall in December and April and to total annual rainfall, as

$$
\begin{gathered}
\text { Relative density }=13.6-0.0051 \text { Rain }_{\text {Total }} \\
+0.0036 \text { Rain }_{\text {December }+ \text { April }} \\
\left(_{2,3}=805, P<.05, R^{2}=0.99\right) .
\end{gathered}
$$

Neither of these variables by themselves explained a significant amount of variation in density. Thus, one of the two independent tests supported previous observations that population density was positively related to rainfall in December and April and negatively related to annual rainfall.

Total population density $[N(t)]$ at Lutz from 1971 through 1989 was related to both previous population density $[N(t-1)]$ and rainfall in the early wet season. The first variable to enter was population density the previous year, as

$$
\begin{gathered}
\log _{10} N(t)=0.48+0.65 \log _{10} N(t-1) \\
\left(F_{1,16}=11.3, P<.01, R^{2}=0.43\right) .
\end{gathered}
$$

The second variable to enter was rainfall in the early wet season $(\mathrm{EW})(P<.05)$. The resultant regression equation was

$$
\begin{gathered}
\log _{10} N(t)=1.75-0.0019 \mathrm{EW}+0.69 \log _{10} N(t-1) \\
\left(F_{2,16}=10.2, P<.01, R^{2}=0.59\right) .
\end{gathered}
$$

No other variable made significant contributions to the model. Again, previous observations are supported. In this case, total population density was negatively related to rainfall in the early part of the wet season, a major component of annual rainfall.

Overall, results of present tests relating population density to rainfall are consistent with previous observations. However, because associations were significant in only two of the three test cases, the association between population density and rainfall must still be considered tenuous.

\section{DISCUSSION}

Stability of Anolis limifrons populations. -Constancy through time is one measure of stability (Pimm and

\begin{tabular}{|c|c|c|c|c|c|c|c|c|c|}
\hline \multirow[b]{2}{*}{ Site } & \multicolumn{2}{|c|}{1983} & \multicolumn{2}{|c|}{1984} & \multicolumn{2}{|c|}{1985} & \multicolumn{2}{|c|}{1986} & \multirow[b]{2}{*}{ Mean } \\
\hline & $\%$ & $n$ & $\%$ & $n$ & $\%$ & $n$ & $\%$ & $n$ & \\
\hline \multicolumn{10}{|l|}{ Mainland } \\
\hline Pipeline & 47 & 30 & 67 & 24 & 50 & 14 & 48 & 21 & $53 \mathrm{bcd}$ \\
\hline \multicolumn{10}{|l|}{ Peninsulas } \\
\hline Bohio & $\cdots$ & $\cdots$ & 71 & 7 & 67 & 3 & 56 & 7 & $65 \mathrm{abc}$ \\
\hline Buena Vista & 94 & 15 & 85 & 13 & 78 & 23 & 78 & 37 & $84 a$ \\
\hline Gigante & $\cdots$ & $\cdots$ & 40 & 10 & 30 & 27 & 67 & 46 & $46 \mathrm{bcd}$ \\
\hline Pena Blanca & $\cdots$ & $\cdots$ & 18 & 11 & 36 & 11 & 29 & 7 & $28 \mathrm{~d}$ \\
\hline \multicolumn{10}{|l|}{ Islands } \\
\hline BCI & 38 & 16 & 45 & 22 & 41 & 61 & 59 & 95 & $46 \mathrm{bcd}$ \\
\hline Juan Gallegos & 33 & 12 & 33 & 9 & 33 & 15 & 36 & 11 & $34 d$ \\
\hline Lion Hill 1 & $\cdots$ & $\cdots$ & 80 & 5 & 82 & 11 & $\cdots$ & $\cdots$ & $81 \mathrm{a}$ \\
\hline Lion Hill 2 & $\cdots$ & 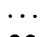 & 28 & 7 & 50 & 8 & 50 & 6 & $43 \mathrm{~cd}$ \\
\hline Puma & 61 & 23 & 79 & 14 & 75 & 28 & 76 & 65 & $73 \mathrm{ab}$ \\
\hline Tigre & 92 & 25 & 80 & 40 & 74 & 31 & 80 & 39 & $82 a$ \\
\hline
\end{tabular}
Redfearn 1988). By this measure, populations of $A$. limifrons are not very stable. Between 1975 and 1976 the population at the Lutz site increased five- (total

TABLE 2. Relative number of young individuals (the percentage of animals with snout-vent length $<44 \mathrm{~mm}$ ) in late wetseason censuses. Means with the same letter are not different $(P>.05$, least significant difference tests). Missing values for 1983 represent censuses excluded from analysis because they were conducted in February. $n=$ number of lizards. 
density) to eight-fold (adult male density). The highest total population density observed at Lutz was in 1978 when the population reached an estimated size of 152 individuals in $890 \mathrm{~m}^{2}$. Population size then decreased steadily and reached extremely low levels in 1983 through 1985 . Such instability would not have been suspected from observations made at Lutz from 1972 through 1974 or from 1983 through 1985 (the 3-yr length of many research projects). The more variable population densities observed from 1975 through 1977 or 1985 through 1987 would still not represent the variability revealed during the $19 \mathrm{yr}$ of this study.

Year-to-year changes of two- to three-fold in relative density were observed at other sites in my study and in total population size at another BCI site as well (Sexton 1967). Four years was too short a period to observe large fluctuations in density at all sites, although year-to-year variation was statistically significant overall, and seven sites exhibited significant yearto-year variation. Thus, outbreaks and crashes appear to be normal for $A$. limifrons populations in central Panama.

How variable are $A$. limifrons populations compared to other lizard populations? Schoener $(1985,1986 a)$ sampled a total of 24 West Indian Anolis populations. Of these, 22 had SD $\log _{10}$ population density in the lowest category of variability ( $<0.21$ SD units). Populations of $A$. limifrons are significantly more variable than West Indian anole populations $(P<.01,2 \times 2$ chi-squared test). This result is in accord with observations of marked year-to-year changes in population density of three other mainland anoles (Campbell 1973, Fitch 1975) and with observations of high year-to-year constancy of population density during a decade-long study of $A$. gingivinus and $A$. wattsi on St. Martin in the West Indies (McLaughlin and Roughgarden 1989).

Schoener (1985) provided SD $\log _{10}$ population density estimates for 12 populations of temperate zone lizards; I located data for 6 more populations. Of these 18 populations, 15 had SD $\log _{10}$ population density in the lowest category of variability. Populations of $A$. limifrons are significantly more variable than temperate zone lizard populations $(P<.05,2 \times 2$ chi-squared test). Thus, populations of these temperature zone lizards (mostly arid lands in North America) are also stable relative to those of $A$. limifrons.

Variability of $A$. limifrons populations increased with the number of censuses, as Connell and Sousa (1983) and Pimm and Redfearn (1988) observed for other taxa. At the Lutz site, the relationship between SD $\log _{10}$ population density and the number of nested censuses has two plateaus, the first apparently associated with "normal" population variability and the second following an unusual environmental perturbation. Data from Lutz thus indicate that at least 6-7 yr (generations) are necessary to assess normal variability for this species.

Year-to-year and long-term changes in population density exhibited by $A$. limifrons populations are especially interesting because of their tropical rainforest habitat. Population fluctuations of $A$. limifrons and other vertebrates (Leigh et al. 1982) as well as arthropods (Wolda 1978a, b) provide evidence that "tropical stability" is not a general paradigm.

\section{Density-dependent interactions}

The negative relationship between index of condition (IC) and population density for $A$. limifrons is not in accord with the suggestion that mainland anoles do not experience intraspecific competition for food (Andrews 1979a). However, competition for food should be relatively weak and episodic in time because of relatively low population densities and wide fluctuations in density through time. In contrast, populations of West Indian anoles should experience stronger and chronic competition for food not only because of their relatively high population densities (Andrews 1979a) but also because of their highly stable populations (Roughgarden et al. 1983, McLaughlin and Roughgarden 1989). Such differences in the nature of intraspecific competition for food between mainland and West Indian anole populations are consistent with the different modes of population regulation proposed for these two geographic areas (Andrews 1979a).

Recruitment was also negatively related to density. At Lutz the relative number of young individuals was lowest at the end of years with high densities and highest at the end of years with low densities, but increased with IC independently of population density. High densities presumably make it more difficult for juveniles to establish territories (Andrews and Rand 1983), but when food is relatively abundant recruitment may be enhanced by reduced competition.

\section{Why do populations of A. limifrons fluctuate in density from year-to-year?}

One explanation for the instability of $A$. limifrons populations is that changes in population density simply reflect responses to a changing local environment. For example, the favorability of small areas could be altered by the predatory activities of a pair of nesting trogons or disturbance due to tree or branch falls. This explanation is unlikely because population fluctuations are synchronous for relatively large areas.

Synchrony of changes in population density at BCI sites from 1983 to 1986 suggests these populations are exposed to a common causal factor. Rainfall is a likely candidate as it varies in quantity and seasonal distribution from year-to-year and nearby locations have more similar rainfall patterns than more distant locations. From 1971 through 1980, 50\% of the variation in population density at the end of the wet season at the Lutz site was explained by the sum of rainfall during the preceeding December and April (Andrews and Rand 1982). Rainfall in December and April is highly variable; January through March is almost invariably dry 
(Rand and Rand 1982). If little rain falls in December and April the dry season is long, and if much rain falls in these months the dry season is short. Thus, the positive association between rain during December and April and population density suggested that population density was affected by the length of the dry season. This makes sense biologically because egg production is reduced during this period (Andrews et al. 1983). However, after four more years of censusing, the association between population density and rainfall in December and April was no longer significant. Instead, population density was negatively associated with total annual rainfall (Andrews and Rand 1990).

Now, with two independent tests of the association between population density and rainfall and a general model based on $19 \mathrm{yr}$ of data at Lutz, the statistical association between population density and rainfall remains weak, but previously identified patterns persist. In general, population density was positively related to the sum of rainfall in December and April and negatively related to total annual rainfall or rainfall in the early wet season. This suggests that $A$. limifrons populations in central Panama do best in years when dry seasons are relatively wet and wet seasons are relatively dry. This pattern is certainly consistent with the distribution of this species; the range of $A$. limifrons is centered in the aseasonal rainforests of Central America's Atlantic lowlands.

Qualitatively, the years of lowest population density (1983-1985) followed extremely unusual climatic events. Rainfall in 1981 was approximately double normal levels, and the dry season of the subsequent "El Niño" year was extremely long (November 1982April 1983) and severe (Windsor et al. 1990). It seems possible that these unusual climatic conditions were associated with the decline in $A$. limifrons populations and with the weak statistical associations between population density and rainfall. Whatever the reason, population density at BCI did not recover appreciably until 1986.

Variation in the amount and timing of annual rainfall is an important abiotic influence on population dynamics in tropical habitats. Such climatic variation is likely to affect populations of $A$. limifrons directly as well as indirectly. For example, desiccation of eggs is likely only during unusually severe dry seasons (Andrews and Sexton 1981). Climatic variation may also act indirectly on anole populations through effects on their predators and on their prey. Eggs and lizards are eaten by a large number of invertebrates including ants, spiders, mantids, and orthopterans and vertebrates including birds, snakes, and other lizards. In turn, $A$. limifrons eat a wide range of invertebrate species. Given the high species diversity of predators on anoles and of their prey and the diverse and presumably independent responses of these species to the physical environment, a weak association between population density of $A$. limifrons and rainfall may not be so surprising.
Apparently erratic population fluctuations can arise from deterministic density-dependent mechanisms (May 1973). Such mechanisms, however, are unlikely to affect population dynamics of $A$. limifrons, at least as projected by rather simple models. First, a plot of $N(t)$ as a function of $N(t-1)$ is linear (at best, weakly asymptotic). "Humped" functions, because they represent time lags for density-dependent interactions, are a necessary condition for populations that overshoot and oscillate around their equilibrium points (May and Oster 1976). Second, with maximal finite rates of increase of 5-8, A. limifrons populations should exhibit damped population fluctuations-only finite rates of increase that are considerably larger are associated with stable limit cycles or chaos (Hassell et al. 1976). Third, the "characteristic return time" for $A$. limifrons populations is large relative to potential time delays, a pattern associated with stable populations (May et al. 1974). Thus, the dynamic nature of population fluctuations of $A$. limifrons is presumably associated with random perturbations that are ameliorated by densitydependent interactions.

\section{Trophic level, life history, and phylogeny}

A broad spectrum of observations suggests that trophic level and body size, as well as other life history attributes, are confounding factors for population stability (Schoener 1986b). For example, populations of insects (Wolda 1978a) and the lizard A. limifrons (Andrews and Rand 1982, this paper) on BCI exhibit population fluctuations that are as high as or higher in amplitude than those of populations in temperate zone areas. In contrast, some birds on BCI exhibit extremely stable population densities over time, apparently as a result of rigid territorial systems that limit populations to numbers well below resource levels (Greenberg and Gradwohl 1986). In the Bahamas, populations of Anolis are more stable than those of their invertebrate prey (Schoener 1986a). These observations suggest that the greater variability of populations of $A$. limifrons in Panama than populations of Anolis in the Bahamas may be related to trophic-level considerations. A. limifrons individuals are middle-level consumers in the complex food webs of mainland tropical forests. In contrast, Anolis lizards are top carnivores on small islands in the Bahamas (Schoener and Spiller 1987). In both situations greater variability is exhibited by the middlelevel consumers-spiders in the Bahamas and Anolis in Panama.

Life history attributes also confound comparisons of stability of West Indian and mainland anole populations. A. limifrons is relatively small and exhibits essentially annual population turnover. Thus generationto-generation changes in population density are almost totally dependent on annual recruitment - a factor that should promote population variability. In contrast, West Indian anoles are considerably larger, and a substantial proportion of their populations survive from 
one year to the next (Andrews 1979a, Schoener and Schoener 1982). Persistence of individuals from one year to the next in West Indian populations should buffer generation-to-generation changes in population density and promote population stability.

Differences in stability between $A$. limifrons and other lizards may also have a phylogenetic component. West Indian and mainland anoles belong to different species groups and clearly have had separate evolutionary histories of millions of years (Williams 1988).

\section{ACKNOWLEDGMENTS}

Funding was provided by the Environmental Sciences Program and post-doctoral fellowship program of the Smithsonian Tropical Research Institute and by NSF Binational Grant No. INT 7605758 to Stan Rand and Steve Ayala and NSF Grants B019801X and GB-37731X to Ernest Williams. I would like to thank Paul Nicoletto, Alan DeQuieroz, Mark Zimmerman, and Anabel Tatis who were my field assistants from 1983 through 1986, respectively, and Brian Bock, Jeff Brawn, Stan Rand, Tom Schoener, Joe Wright, and an anonymous reviewer for their comments on the manuscript.

\section{Literature Cited}

Abts, M. L. 1987. Environment and variation in life history traits of the chuckwalla, Sauromalus obesus. Ecological Monographs 57:215-232.

Andrews, R. M. 1979a. Evolution of life histories: a comparison of Anolis from matched island and mainland habitats. Breviora 454:1-51.

1979b. Reproductive effort of female Anolis limifrons (Sauria: Iguanidae). Copeia 1979:620-626.

. 1982a. Patterns of growth in reptiles. Pages 273320 in C. Gans and F. H. Pough, editors. Biology of th Reptilia. Volume 13, Physiology: D. Physiological ecology. Academic Press, New York, New York, USA.

$\longrightarrow \rightarrow-$. 1982b. Spatial variation in egg mortality of the lizard Anolis limifrons. Herpetologica 38:165-171.

- 1988. Demographic correlates of variable egg survival for a tropical lizard. Oecologia (Berlin) 76:376-382.

Andrews, R. M., and J. D. Nichols. 1990. Survival of a small tropical lizard. Oikos 57:215-221.

Andrews, R. M., and A. S. Rand. 1982. Seasonal breeding and long-term population fluctuations in the lizard Anolis limifrons. Pages 405-412 in E. G. Leigh, A. S. Rand, and D. M. Windsor, editors. The ecology of a tropical forest: seasonal rhythms and long-term changes. Smithsonian Institution Press, Washington, D.C., USA.

Andrews, R. M., and A. S. Rand. 1983. Limited dispersal of juvenile Anolis limifrons. Copeia 1983:429-434.

Andrews, R. M., and A. S. Rand. 1990. Reproducción estacial y fluctuaciones poblacionales a largo plazo de la lagartija Anolis limifrons. Adición: neuvas percepciones derivadas de la continuación de un estudio a largo plazo de la lagartija Anolis limifrons. Pages 469-479 in E. G. Leigh, A. S. Rand, and D. M. Windsor, editors. Ecología de un bosque tropical: ciclos estacionales y cambios a largo plazo. Smithsonian Institution Press, Washington, D.C., USA.

Andrews, R. M., A. S. Rand, and S. Guerrero. 1983. Seasonal and spatial variation in the annual cycle of a tropical lizard. Pages 441-454 in A. G. J. Rhodin and K. Miyata, editors. Advances in herpetology and evolutionary biology, essays in honor of Ernest E. Williams. Museum of Comparative Zoology, Harvard University, Cambridge, Massachusetts, USA.

Andrews, R. M., and O. J. Sexton. 1981. Water relations of the eggs of Anolis auratus and Anolis limifrons. Ecology 62: 556-562.
Campbell, H. W. 1973. Ecological observations on Anolis lionotus and Anolis poecilopus (Reptilia, Sauria) in Panama. American Museum Novitates 2516:1-29.

Connell, J. H. 1978. Diversity in tropical rainforests and coral reefs. Science 199:1302-1310.

Connell, J. H., and W. P. Sousa. 1983. On the evidence needed to judge ecological stability or persistence. American Naturalist 121:789-824.

Dobzhansky, T. 1950. Evolution in the tropics. American Scientist 38:209-221.

Ferguson, G. W., C. H. Bohlen, and H. P. Woolley. 1980. Sceloporus undulatus: comparative life history and regulation of a Kansas population. Ecology 61:313-322.

Fitch, H. S. 1975. Sympatry and interrelationships in Costa Rican anoles. Occasional Papers, University of Kansas Museum of Natural History 40.

Fogden, M. P. L. 1972. The seasonality and population dynamics of equatorial forest birds in Sarawak. Ibis 114: 307-343.

Foster, R. B. 1982. Famine on Barro Colorado Island. Pages 201-212 in E. G. Leigh, A. S. Rand, and D. M. Windsor, editors. The ecology of a tropical forest: seasonal rhythms and long-term changes. Smithsonian Institution Press, Washington, D.C., USA.

Foster, R. B., and N. V. L. Brokaw. 1982. Structure and history of the vegetation of Barro Colorado Island. Pages 67-81 in E. G. Leigh, A. S. Rand, and D. M. Windsor, editors. The ecology of a tropical forest: seasonal rhythms and long-term changes. Smithsonian Institution Press, Washington, D.C., USA

Gibbs, H. L., and P. R. Grant. 1987. Ecological consequences of an exceptionally strong El Niño event on Darwin's finches. Ecology 68:1735-1746.

Goodman, D. 1975. The theory of diversity-stability relationships in ecology. Quarterly Review of Biology 50:237266.

Greenberg, R., and J. Gradwohl. 1986. Constant density and stable territoriality in some tropical insectivorous birds. Oecologia (Berlin) 69:618-625.

Hassell, M. P., J. H. Lawton, and R. M. May. 1976. Patterns of dynamical behaviour in single-species populations. Journal of Animal Ecology 45:471-486.

Hengeveld, R., and J. Haeck. 1982. The distribution of abundance. I. Measurements. Journal of Biogeography 9: 303-316.

Hutchinson, G. E. 1959. Homage to Santa Rosalia, or why are there so many kinds of animals? American Naturalist 93:145-159.

Jones, S. M., and R. E. Ballinger. 1987. Comparative life histories of Holbrookia maculata and Sceloporus undulatus in western Nebraska. Ecology 68:1828-1838.

Leigh, E. G., Jr., A. S. Rand, and D. M. Windsor. 1982. The ecology of a tropical forest: seasonal rhythms and long-term changes. Smithsonian Institution Press, Washington, D.C., USA.

MacArthur, R. H., and E. O. Wilson. 1967. The theory of island biogeography. Princeton University Press, Princeton, New Jersey, USA.

May, R. M. 1973. Stability and complexity in model ecosystems. Princeton University Press, Princeton, New Jersey, USA.

May, R. M., G. R. Conway, M. P. Hassell, and T. R. E. Southwood. 1974. Time delays, density-dependence, and single-species oscillations. Journal of Animal Ecology 43: 747-770.

May, R. M., and G. F. Oster. 1976. Bifurcations and dynamic complexity in simple ecological models. American Naturalist 110:573-599.

McLaughlin, J. F., and J. Roughgarden. 1989. Avian predation on Anolis lizards in the northeastern Caribbean: an inter-island contrast. Ecology 70:617-628. 
Odum, E. P. 1971. Fundamentals of ecology. Third edition. W. B. Saunders, Philadelphia, Pennsylvania, USA.

Pimm, S. L., and A. Redfearn. 1988. The variability of population densities. Nature 334:613-614.

Poole, R. W. 1974. An introduction to quantitative ecology. McGraw-Hill, New York, New York, USA.

Rand, A. S., S. Guererro, and R. M. Andrews. 1983. The ecological effects of malaria on populations of the lizard Anolis limifrons on Barro Colorado Island, Panama. Pages 455-471 in A. G. J. Rhodin and K. Miyata, editors. Advances in herpetology and evolutionary biology, essays in honor of Ernest E. Williams. Museum of Comparative Zoology, Harvard University, Cambridge, Massachusetts, USA.

Rand, A. S., and W. M. Rand. 1982. Variation in rainfall on Barro Colorado Island. Pages 47-59 in E. G. Leigh, A. S. Rand, and D. M. Windsor, editors. The ecology of a tropical forest: seasonal rhythms and long-term changes. Smithsonian Institution Press, Washington, D.C., USA.

Ricklefs, R. E. 1973. Ecology. Chiron, Newton, Massachusetts, USA.

Roughgarden, J., D. Heckel, and E. R. Fuentes. 1983. Coevolutionary theory and the biogeography and community structure of Anolis. Pages 371-410 in R. B. Huey, E. R. Pianka, and T. W. Schoener, editors. Lizard ecology: studies of a model organism. Harvard University Press, Cambridge, Massachusetts, USA.

SAS Institute. 1982. SAS user's guide: statistics. 1982 edition. SAS Institute, Cary, North Carolina, USA.

Schoener, T. W. 1985. Are lizard population sizes unusually constant through time? American Naturalist 126:633-641.

- 1986a. Patterns in terrestrial vertebrate versus arthropod communities: do systematic differences in regularity exist? Pages 556-586 in J. Diamond and T. J. Case, editors. Community ecology. Harper \& Row, New York, New York, USA

- 1986b. Overview: kinds of ecological communities-ecology becomes pluralistic. Pages 467-479 in J. Diamond and T. J. Case, editors. Community ecology. Harper $\&$ Row, New York, New York, USA.

Schoener, T. W., and A. Schoener. 1982. The ecological correlates of survival in some Bahamian Anolis lizards. Oikos 39:1-16.

Schoener, T. W., and D. A. Spiller. 1987. Effect of lizards on spider populations: manipulative reconstruction of a natural experiment. Science 236:949-952.

Sexton, O. J. 1967. Population changes in a tropical lizard Anolis limifrons on Barro Colorado Island, Panama Canal Zone. Copeia 1967:219-222.
Sexton, O. J., J. Bauman, and E. Ortleb. 1972. Seasonal food habits of Anolis limifrons. Ecology 53:182-186.

Sexton, O. J., H. Heatwole, and D. Knight. 1964. Correlation of microdistribution of some Panamanian reptiles and amphibians with structural organization of the habitat. Caribbean Journal of Science 4:261-295.

Sexton, O. J., E. P. Ortleb, L. M. Hathaway, R. E. Ballinger, and P. Licht. 1971. Reproductive cycles of three species of anoline lizards from the Isthmus of Panama. Ecology 52: 201-215.

Siegel, S. 1956. Nonparametric statistics. McGraw-Hill, New York, New York, USA.

Strijbosch, H., and R. C. M. Creemers. 1988. Comparative demography of sympatric populations of Lacerta vivipara and Lacerta agilis. Oecologia (Berlin) 76:20-26.

Terborgh, J. 1986. Keystone plant resources in the tropical forest. Pages 330-344 in M. E. Soule, editor. Conservation biology: the science of scarcity and diversity. Sinauer, Sunderland, Massachusetts, USA.

Thorington, R. W., B. Tannenbaum, A. Tarak, and R. Rudran. 1982. Distribution of trees on Barro Colorado Island: a five-hectare study. Pages 83-94 in E. G. Leigh, A. S. Rand, and D. M. Windsor, editors. The ecology of a tropical forest: seasonal rhythms and long-term changes. Smithsonian Institution Press, Washington, D.C., USA.

Williams, E. E. 1988. A new look at the Iguania. Pages 429486 in W. R. Heyer and P. E. Vanzolini, editors. Proceedings of a workshop on neotropical distribution patterns. Academia Brasileira de Ciencias, Rio de Janeiro, Brazil.

Windsor, D. M. 1990. Climate and moisture variability in a tropical forest: long-term records from Barro Colorado Island, Panamá. Smithsonian Contributions to the Earth Sciences 29.

Windsor, D. M., A. S. Rand, and W. M. Rand. 1990. Características de la precipitación de la isla de Barro Colorado. Pages 53-71 in E. G. Leigh, A. S. Rand, and D. M. Windsor, editors. Ecología de un bosque tropical: ciclos estacionales y cambios a largo plazo. Smithsonian Institution Press, Washington, D.C., USA.

Wolda, H. 1978a. Fluctuations in abundance of tropical insects. American Naturalist 112:1017-1045.

. 1978b. Seasonal fluctuations in rainfall, food and abundance of tropical insects. Journal of Animal Ecology 47:369-381.

Wright, S. J., R. Kimsey, and C. J. Campbell. 1984. Mortality rates of insular Anolis lizards: a systematic effect of island area? American Naturalist 123:134-142. 